\title{
Manuel Bandeira: entre o lírico e o empírico
}

\section{Rosilene Silva da Costa*}

\begin{abstract}
Resumo: Este artigo busca refletir sobre a lírica moderna, no que concerne ao sujeito lírico. É ponto pacífico que na modernidade há uma dissociação entre o sujeito lírico e o sujeito empírico na poesia, porém quando chegamos em Manuel Bandeira isto não aparece tão claro, por isso buscamos discutir este conceito a fim de tentar dar conta do fenômeno que ocorre neste poeta brasileiro.
\end{abstract}

\begin{abstract}
This article aims at reflecting on the modern lyric, specifically on what concerns the speaker. It is an uncontroversial point that in modernity there is - in poetry - a dissociation between the speaker and the poet. However when we read Manuel Bandeira this is not so clear; therefore we aim to argue on the concept of the speaker in order to analyze the phenomenon that occurs in the work of this Brazilian poet.
\end{abstract}

Keywords: speaker, Modernism, poet, poetry.

Palavras-chave: eu lírico, Modernismo, poeta, poesia.

\section{Lírica moderna: espaço de despersonificação dos sujeitos}

A lírica moderna, mais propriamente dita a lírica européia do século XX, não possui um fácil acesso, pois é enigmática e obscura. As obras de líricos como Rilke (alemão), Apolinnaire (francês) e T. S. Elliot (anglo-saxônico) têm uma significação indubitável, já que mostram que a expressão da lírica não é inferior à força de expressão de outras artes como o romance, teatro, pintura, música até mesmo da filosofia.

Em seu estudo sobre a lírica moderna, Hugo Friedrich identifica na obscuridade presente na obra destes poetas e de seus contemporâneos um elemento que faz com que o leitor fique fascinado, embora consiga também desconcertá-lo. Há uma certa magia nas palavras e um ar de mistério nos sentidos que, ao agirem profundamente sobre o leitor, o prendem, mesmo quando a compreensão permaneça desorientada.

Esta obscuridade é proposital, pois esses poetas não desejam que a compreensão esteja realmente acessível. Baudelaire diz que há uma glória em não ser entendido. Diante disso, aquele que se propõe a ser leitor da lírica moderna precisa acostumar-se com esse dia nublado que ela apresenta, pois ela tende a se manter cada vez mais afastada da mediação. Deseja ser

\footnotetext{
* Rosilene Silva da Costa é Licenciada em Letras pela UFRGS, mestranda do PPG-Letras/UFRGS, especialidade Literatura Brasileira e Luso-africana. É professora da rede municipal de Porto Alegre desde 2002.
} 
algo auto-suficiente e com uma pluralidade de formas e significações. Tendo estas características, será a geradora de uma tensão.

Essa tensão dissonante, que se instala no interior da lírica, transcende os limites da forma e do lingüístico, e aparece também no conteúdo. Na referência que faz ao conteúdo das coisas e dos homens, conduz o leitor ao estranhamento, deformando o objeto ou o ser do qual fala. Apesar de o ponto de partida dessa nova poesia ser o real, ela não mais anseia ser medida pela realidade comum:

A realidade desprendeu-se da ordem espacial, temporal, objetiva e anímica e subtraiu as distinções - repudiada como prejudiciais -, que são necessárias a uma orientação normal do universo: as distinções entre o belo e o feio, entre a proximidade e a distância, entre a luz e a sombra, entre a dor e a alegria, entre a terra e o céu. Das três maneiras possíveis de comportamento da composição lírica - sentir, observar, transformar, é a última que domina na poesia moderna e, em verdade, tanto no que diz respeito ao mundo como à língua (FRIEDRICH, 1978, p.17).

Ainda segundo Friedrich, a poesia moderna pode ser entendida como dotada de uma dramaticidade agressiva, que visa chocar seu leitor. A tensão na linguagem associada à obscuridade dos conteúdos gera uma perturbação, fazendo com que a língua poética assemelhe-se a um experimento, o qual é criador de um significado não necessariamente pretendido.

Diante dos fenômenos como dissonância, obscuridade, significações insólitas e dramaticidade agressiva instala-se no leitor a impressão de uma anormalidade, concordando com o conceito de Friedrich que fala de surpresa e estranhamento.

\section{0 poeta despersonificado}

A palavra modernidade tem Baudelaire como um dos seus criadores, pois ele a emprega em 1859, quando começa a necessitar dela para expressar a singularidade do artista moderno.

Baudelaire problematiza, ou tem como um de seus problemas específicos, a possibilidade da existência de poesia numa civilização comercializada e dominada pela técnica. Sua poesia acaba sendo o indicador da via a ser seguida, buscando a maior distância daquilo que é trivial no âmbito da realidade, ela anseia por uma zona de mistério.

Disciplina espiritual e clareza de sua consciência artística são características fundamentais de Baudelaire, pois ele reúne o gênio poético e a inteligência crítica com o fim de mostrar que suas idéias acerca do procedimento da arte poética estão no mesmo nível do seu próprio poetar e, em muitas vezes, estão além dele. 
A principal característica que achamos no autor de Les Fleurs du Mal é o fato de sua lírica ser confessional, embora nela penetre todo o sofrimento de um homem solitário, infeliz e doente. A poesia deste autor não é datada, a exemplo do que faziam outros autores, portanto, não há nenhuma base que possa explicar em seus temas as questões biográficas. Em Baudelaire, inicia-se a despersonalização da lírica moderna, ou seja, a palavra lírica não é mais gerada das unidades de poesia e pessoa empírica, como os românticos pretendiam, a fim de contrastar com o lirismo de outros séculos.

Edgar Allan Poe também busca, ou melhor, faz essa separação entre a lírica e o sujeito empírico, porém é mais enfático, pois desconecta a lírica do coração. Para ele a lírica deve ser de uma excitação entusiástica, mas dissociada das paixões do poeta. A produção moderna é cada vez mais caracterizada pelo "não-coração", ou seja, o poeta assume o papel defendido por Fernando Pessoa: o de fingidor.

O desejo de fantasia dentro da arte poética vai levando o homem a racionalizar cada vez mais o seu fazer poético, o que o afasta de si mesmo, como pessoa, para poetar sobre aquilo que é do mundo real, embora não do mundo comum.

Rimbaud também trabalha com a despersonificação do poeta. As suas experiências até podem contribuir para explicar psicologicamente os seus textos, porém não servem para explicar o eu lírico, pois este eu é composto por uma multiplicidade dissonante de vozes produto do estilo imaginativo do qual nascem os conteúdos de suas poesias.

Portanto, em Baudelaire e em Rimbaud, começa a separação anormal entre o sujeito poético e o sujeito empírico, que, para nós, na atualidade, é comum.

Essa separação nos permite entender a lírica moderna não mais como uma simples expressão biográfica, mas sim como uma produção artística que é fruto, sobretudo, do fazer racional de um indivíduo.

\section{Modernidade na lírica brasileira}

A modernidade na lírica brasileira parece partir de uma desestruturação para uma estruturação. Isso quer dizer que o lirismo brasileiro, assim como o de outros países, começa a ser desestruturado de seus conceitos para estruturar novos conceitos. O que é diferente no Brasil é que isso ocorre gradativamente, tanto na voz de um poeta que atravessa as várias fases do modernismo, como em poetas que iniciam tendo como base a modernidade. 
Embora não se busque fundamentar nossa análise no estruturalismo, usaremos o termo estrutura para significar o que queremos dizer em termos de lírica moderna. Para isso usaremos o conceito de Pierre Francastel para este termo:

Não se fala de estrutura em estética, para designar a conformidade a um plano, mas para caracterizar a maneira como o plano foi realizado por combinação de elementos que não estavam necessariamente incluídos nas premissas do empreendimento. Aproximamo-nos assim antes da noção de objeto - que é o produto final e empírico de uma atividade em que os móveis meios são múltiplos - que da noção de forma. Exclui-se em todo caso a idéia de que estrutura corresponde a ressaltar uma realidade exaustiva e constrangedora. E ela é antes resultado de um projeto do que justificada pelo desejo de reprodução de um modelo (LIMA, 1995, p.18).

Reconhecemos que a linguagem é uma rede de significações verbalmente estabelecidas, através da qual o homem não apenas fundamenta o que já sabe, mas também problematiza o novo que desconhecia. A linguagem também é entendida como um elemento modificado e propulsionado pela cultura, logo a linguagem se modifica para atender as demandas da sociedade, que constantemente muda. Dentro desta dinamicidade da linguagem estão os termos estruturação e desestruturação. Não queremos dizer que a estruturação da linguagem se transforme na sua sintaxe e morfologia, porque a sociedade muda, mas sim que a sintaxe social interfere no léxico, deixando-o desatualizado, no sentido de criar novos termos ou de dar novos sentidos aos já existentes. A maneira de estruturação da linguagem criadora tendencialmente muda a visão de mundo, o que sempre será uma visão de classes, apoiada na linguagem. Desta forma podemos dizer que a linguagem não será eternamente a mesma, assim como não será imutável a estrutura de sua representação, pois a visão de mundo muda com o passar do tempo.

No Brasil, a virada do século foi marcada pelos movimentos de vanguarda nas diversas artes, que deram início ao que chamamos de Modernismo Brasileiro.

Enquanto na Europa esse modernismo começava nas grandes metrópoles, aqui, no Brasil, ele tinha os primeiros focos nas cidades precariamente urbanizadas, pois o país ainda girava muito em torno da base agrícola-latifundiária. Logo os poetas se inspiraram em Baudelaire, mas não poderiam iniciar como ele falando de estar sozinho em meio das multidões da cidade. Mesmo assim, os poetas desse período lançam-se na empreitada de uma nova forma lírica, que começará por desestruturar a lírica antiga para dar forma a uma nova arte poética.

Neste momento encontramos um sujeito chamado Manuel Bandeira, que é considerado o precursor do Modernismo no Brasil. Manuel Bandeira é nascido no final do século XIX, em Pernambuco, muda-se para o Rio de Janeiro no início do século XX e, anos mais tarde, quando principia sua juventude, terá contato com poetas europeus na Suíça, 
quando buscava tratamento de saúde. Ele atravessa todas as fases da produção moderna, pois viveu até o ano de 1968, tendo publicado o seu último livro em 1966.

Com Bandeira começará a desestruturação da poesia antiga para estruturação da poesia moderna. Isto ocorrerá de forma gradativa, pois os seus livros até 1930 terão traços bem marcados do Parnasianismo, do Simbolismo e até mesmo do Romantismo.

Os traços mais visíveis da transição de épocas em Bandeira estão na forma fixa, no vocabulário rebuscado, na sonoridade dos poemas e nos temas. Sobre a última característica os temas - é que nos deteremos, pois vemos neles uma marca significativa do nosso ponto principal de discussão: a despersonalização do poeta na lírica moderna.

Em Manuel Bandeira essa despersonalização será gradual. Somente após a publicação do quarto livro é que poderemos perceber uma dissociação clara entre o lírico e o empírico na sua obra, pois ela é atravessada por fragmentos do seu cotidiano, que estão intrinsecamente ligados a questões biográficas. Ao contrário de Baudelaire, o poeta data seus poemas, permitindo a aproximação entre eles e os fatos da sua vida, mas não somente isso leva-nos a pensar que o biográfico está presente em sua obra, assim como está presente na obra dos Românticos. Ele escreve um livro autobiográfico, onde fala da ligação direta da sua produção lírica com sua vida, chegando a criticar severamente o seu primeiro livro por estar tomado de seus sentimentos como forma de desabafo.

T. S. Elliot, poeta e crítico moderno, afirma que a função maior da poesia é dar um prazer que somente a poesia pode dar, no entanto, todo bom poeta tem algo além do prazer a oferecer:

a comunicação de alguma experiência nova, de algum entendimento novo do familiar, ou a expressão de alguma coisa que sentimos mas para a qual não temos palavras, que amplia nossa conscientização ou apura nossa sensibilidade (ELLIOT, 1972, p.32).

Bandeira consegue esses dois efeitos em sua poesia, pois a todo instante traz experiências que são suas e que também fazem parte das angústias humanas, logo cumprindo as duas exigências de Elliot.

Para Fernando Pessoa, o poeta é um fingidor, pois ele não necessariamente precisa sentir em si, na sua carne ou na sua alma, aquilo que escreve. Para Pessoa, a poesia é ficção, fabricação e não representação do real.

Contudo, quando chegamos em Bandeira, encontramos um desequilíbrio na teoria moderna do "eu lírico dissociado do sujeito empírico", pois muitas vezes o biográfico surge na poesia de Bandeira. Ao ligar suas vivências a sua obra, o poeta rasura um dos pressupostos do Modernismo, já que não busca um estranhamento face ao real, porém incorpora o real na 
poesia. Isso de certa forma pode estar ligado ao pressuposto modernista do poeta ser um incompreendido no mundo.

Analisando a poesia de Bandeira, em conjunto com os seus relatos biográfico, encontramos muitos pontos em comum entre a sua vida e a sua obra, fato que nos obriga a pensar que o autor consegue transpor com genialidade mais uma característica moderna, ou seja, Bandeira escreve de forma diferente do seu tempo. Embora a todo o momento ensine muito sobre a poética moderna, o autor consegue realmente um lirismo que é libertação. Libertação que os poetas buscam na linguagem da poesia.

Essa liberdade, tão evocada no célebre poema "Vou-me embora pra Pasárgada", é o ponto central da obra de Bandeira, pois o poeta se mostra livre em toda sua trajetória. Livre na forma dos seus versos, que foram de sonetos a versos livres. Livre na sua temática, a qual bebeu desde os gregos até notícias tiradas do jornal do dia. E a principal liberdade que encontramos em Bandeira está relacionada ao momento histórico de sua lírica, afinal o poeta começa escrevendo num momento de transição não somente da poesia moderna, mas de todas as formas de arte e, mesmo assim, consegue ser ímpar a ponto de ter a sua própria poética.

Percebemos, neste poeta livre de modismos, escolas e idéias, mas iniciador do Modernismo Brasileiro, a desestruturação da lírica antiga para a estruturação da lírica moderna, que é evidente em diversos aspectos de sua obra, porém mais contundente nas questões referentes ao eu lírico, pois ele, ao parecer misturar sua vida com sua obra e ao escrever sua autobiografia, instaura um novo em poesia, que é falar de si mesmo, quando não se é o mesmo. Isso parece confuso, mas Bandeira criou um eu lírico muito parecido com ele mesmo, alguém que tem as mesmas dificuldades que se imagina que o poeta tinha e que aparecem de alguma forma em suas confissões em prosa, mas de forma alguma poderíamos dizer que sua poesia se restringe a um ato confessional. Ela é antes de tudo o trabalho consciente de alguém que com genialidade consegue ser moderno, como se espera de alguém de seu tempo, sem se desprender da forma, da musicalidade e dos sentimentos. A isso chamaremos liberdade poética e a ele o precursor de uma libertação que viria mais tarde com os "Jesus Cristos" do modernismo e com a sua própria lírica que atravessa todas as chamadas fases do Modernismo Brasileiro.

Logo a nossa conclusão é: Bandeira é o gênio iniciador da poesia moderna no Brasil, aquele que com graça, sutileza e humildade faz um trabalho artístico consciente, que ainda hoje, quase cinqüenta anos depois de sua morte e a quase cem anos de sua primeira publicação, deixa estudantes e leitores extasiados ante a sua poética que é a verdadeira libertação. 


\section{Referências}

ARRIGUCI, Davi, Humildade, Paixão e Morte: A Poesia de Manuel Bandeira. São Paulo: Companhia das Letras, 1990.

BANDEIRA, Manuel. Poesia Completa e Prosa. Rio de Janeiro: Nova Aguilar, 1986. . Itinerário de Pasárgada. Rio de Janeiro: Jornal de Letras, 1986.

BASTIDE, Roger. Poetas do Brasil.São Paulo: USP, 1997.

ELLIOT, T.S. A essência da poesia. São Cristóvão: Arte Nova, 1972.

FRIEDRICH, Hugo. Estrutura da lírica moderna. São Paulo: Duas Cidades, 1978.

LIMA, Luiz Costa. Lira e Antilira. Rio de Janeiro: Topbooks, 1995. 